\title{
Ashwagandha Extract as Green Sustainable Corrosion Inhibitor for Aluminum in Acidic Solutions
}

\author{
Abd El-Aziz S. Fouda ${ }^{1}$ (D), Safaa El-din H. Etaiw ${ }^{2}$ (D), Mohamed M. Bakr ${ }^{1,2}$, Kamal. Shalabi ${ }^{1, *(D)}$ \\ 1 Chemistry Department, Faculty of Science, Mansoura University, Mansoura, Egypt; asfouda@hotmail.com (A.S.F.); \\ mohamed_bakr9292@yahoo.com (M.M.B.); \\ 2 Chemistry Department, Faculty of Science, Tanta University, Tanta, Egypt; safaaetaiw@ hotmail.com (S.H.E.); \\ * Correspondence: dr-kamal@mans.edu.eg;
}

Scopus Author ID 26667157900

Received: 20.08.2020; Revised: 10.09.2020; Accepted: 14.09.2020; Published: 16.09.2020

\begin{abstract}
In this study, the employment of Ashwagandha extract (AE) as a green sustainable corrosion inhibitor for aluminum in one molar hydrochloric acid solutions was examined utilizing "mass loss (ML), electrochemical frequency modulation (EFM), electrochemical impedance spectroscopy (EIS) and potentiodynamic polarization (PP) measurements". The surface examination was analyzed utilizing atomic force microscopy (AFM) and X-ray photoelectron spectroscopy (XPS) analysis. The effect of temperature on corrosion demeanor with adding a different dose of $\mathrm{AE}$ was investigated within the temperature varieties of $25-45^{\circ} \mathrm{C}$ by $\mathrm{ML}$ strategy. The curves of polarization reveal that $\mathrm{AE}$ is considered as a mixed sort inhibitor. The performance of inhibition rises with raising the $\mathrm{AE}$ concentration and diminished with the temperature ascending. The adsorption of the inhibitor on aluminum surface complies with the Langmuir's adsorption isotherm and is considered as physisorption. The outcomes attained from chemical and electrochemical methods are in good accord.
\end{abstract}

Keywords: Al; corrosion inhibition; HCl; Ashwagandha; EIS; EFM; AFM; XPS.

(C) 2020 by the authors. This article is an open-access article distributed under the terms and conditions of the Creative Commons Attribution (CC BY) license (https://creativecommons.org/licenses/by/4.0/).

\section{Introduction}

Al and its alloys are a crucial construction material owing to their extraordinary advanced data and the board variety of mechanical applications, transcendently in flying, vehicles, and nuclear unit. Al alloys are used in a broad assortment of business because of their different appealing properties such as good mechanical properties, lightweight, high conductivity, and resistance to corrosion [1]. Generally, famous acid inhibitors are organic compounds, including $\mathrm{N}, \mathrm{S}$, and $\mathrm{O}$ atoms, which have high inhibition efficiencies [2-5]. The heterocyclic organic compounds have been utilized as corrosion inhibitors for $\mathrm{Fe}$ [6-9], $\mathrm{Cu}$ [10], Al [11-13], and different metals [14-15] in various corrosive media. However, numerous of these compounds have great hindrance performance, various of them have undesirable effects, even in greatly little concentrations, because of their poisonousness to humans, harmful environmental effects, and critical cost [16]. Plant extract is economical and environmentally safe, so they are considered as ecofriendly corrosion inhibitors. Recently, several plant extracts have been utilized as powerful corrosion inhibitors for Al alloy in Hydrochloric acid solutions, such as Garlic [17], Black Mulberry [18], piper Guineans seed [19] Red onion skin [20]. The inhibition capability of these extract is ordinarily attributed to the presence of organic species containing tannins, alkaloids and nitrogen bases, carbohydrates, and proteins in their constituents. These compounds commonly include polar functions with $\mathrm{N}, \mathrm{S}$, or $\mathrm{O}$ atoms and 
have triple or conjugated double bonds with aromatic rings in their molecular structures, which are the significant adsorption centers. The Ashwagandha plant is the Solanaceae or nightshade family and contains flavonoids, withanolides, alkaloids, steroids, and antioxidants are found in all pieces of the plant, particularly the roots [21]. This plant, especially its root powder, has been utilized in traditional Indian medicine for a long time and dietary supplements containing ashwagandha [22]. This study is to show the inhibition features of the AE and investigate the corrosion protection ability by using ML, PP, EIS, and EFM measurements. The surface analysis of the Al metal was analyzed by using AFM and XPS. The temperature effect on the rate of corrosion and thermodynamic parameters were decided and talked about.

\section{Materials and Methods}

\subsection{Materials and solutions.}

Corrosion examinations have been operated on $\mathrm{Al}$ specimens with the chemical constituents: $0.05 \mathrm{Mg}$; $0.05 \mathrm{Cr}$; $0.05 \mathrm{Ti} ; 0.10 \mathrm{Cu}$; $0.30 \mathrm{Si} ; 0.60 \mathrm{Fe} ; 1.40 \mathrm{Mn}$, and the rest is $\mathrm{Al}$. The corrosive solution utilized was arranged by dilution of analytical reagent grade $34 \%$ hydrochloric acid with doubly distilled water. The stock solution (1000 ppm) of Ashwagandha was utilized to get ready the desirable concentrations by dilution with doubly distilled water.

\subsection{Plant extract preparation.}

A fine powder of the Ashwagandha plant was prepared by grinding the dried Ashwagandha plant roots. The resulted powder materials around $250 \mathrm{~g}$ were dipped in 0.5 liter dichloromethane for 120 hours and after that imperiled to recurrent removal with $5 \times 50 \mathrm{ml}$ to extract plant materials. Afterward, dichloromethane was evaporated, a solid extract was obtained then prepared to be applied as a corrosion inhibitor. Chemicals examine exhibited that the major chemical compositions of Ashwagandha are alkaloids, solasodine, withanolides, flavonoids, steroidal lactones, and saponins [22].

\subsection{ML method.}

Pre-weighed aluminum specimens were immersed in 0.1 liters of one molar hydrochloric acid in the lack and existence of the various concentrations of AE varying from 50 to $300 \mathrm{ppm}$. Afterward, diverse immersion time, the specimens were taken out, rinsed with doubly distilled water, dehydrated, and weighted precisely [23]. The inhibition efficiency (IE\%) and surface coverage degree, $\theta$ of AE were determined as follows:

$$
I E \%=\theta \times 100=\left[1-\frac{W}{W^{\circ}}\right] \times 100
$$

"where $\mathrm{W}^{\mathrm{o}}$ and $\mathrm{W}$ are the average ML before and after adding the inhibitor, individually."

\subsection{Electrochemical measurements.}

Electrochemical techniques were done utilizing a typical three electrodes thermostatic cell containing the working electrode $\left(1 \mathrm{~cm}^{2}\right)$ was aluminum, the counter electrode was a platinum sheet, and the reference electrode was a saturated calomel electrode (SCE). The working electrode was polished utilizing emery paper up to 1200 grades. Then, the Al electrode was washed with double-distilled water. This arrangement was immersed in one molar hydrochloric acid as perfect destructive media. All tests were achieved at $25^{\circ} \mathrm{C}$. 
The PP measurements were conducted by sweeping the potential from -280 to +200 $\mathrm{mV} \mathrm{SCE}$ with a sweeping rate of $1 \mathrm{mV} \mathrm{s}^{-1}$ after the working electrode reached steady-state (30 $\mathrm{min}$ ) and the open circuit potential (OCP) was acquired. EIS measurements were executed within the frequency run $\left(10^{5}\right.$ to $\left.0.1 \mathrm{~Hz}\right)$ with an amplitude of $5 \mathrm{mV}$ peak-to-peak utilizing ac signals at open circuit potential. The most parameters concluded from the examination of the Nyquist chart are the polarization resistance $R_{p}$ and the capacity of double-layer $C_{d l}$, which is characterized:

$$
\mathrm{C}_{\mathrm{dl}}=\frac{1}{2 \pi f_{\max R}}
$$

"where $f_{\max }$ is the hiegest frequency at which the imaginary component of the impedance reaches to its highest values". The productivity of the hindrance and the scope of the surface $(\Theta)$ gotten from the impedance estimations are characterized by the subsequent relation:

$$
\% I E=\left(1-\frac{R_{p}^{\circ}}{R_{p}}\right) \times 100
$$

"where $\mathrm{R}_{\mathrm{p}}^{0}$ and $\mathrm{R}_{\mathrm{p}}$ are the polarization resistance before and after adding the inhibitor, accordingly".

EFM measurements were performed utilizing at 2 and $5 \mathrm{~Hz}$ of frequencies. The base frequency was $0.1 \mathrm{~Hz}$, so the wave repeated after $1 \mathrm{~s}$. The intermodulation spectra include current response comes from for harmonic and intermodulation current peaks. The bigger peaks were utilized to evaluate the corrosion current density ( $i_{c o r r}$ ), the Tafel slopes ( $\beta_{\mathrm{a}}$ and $\beta_{\mathrm{c}}$ ), and the causality factors $\mathrm{CF}_{2}$ and $\mathrm{CF}_{3}[24,26]$. The open-circuit potential was permitted to steady for a half-hour after this time the estimations recently beginning. Tests were conducted at room temperature $25 \pm 1{ }^{\circ} \mathrm{C}$. Estimations were executed employing Gamry Instrument with the Gamry framework. Beside Echem analyst v.5.03 program was utilized for plotting and fitting the outcomes data [24-26].

\subsection{Surface morphology using AFM and XPS analysis.}

Surface morphology of polished aluminum samples prior to and following immersion in one molar hydrochloric acid. In the lack and existence of AE for $24 \mathrm{hrs}$. were executed utilizing Nano Surf Easy scan 2 Flex AFM instruments. In addition, X-ray photoelectron spectroscopy (XPS) measurements were executed utilizing ESCALAB 250Xi, Thermo Scientific, USA.

\section{Results and Discussion}

\subsection{ML measurements.}

Aluminum mass loss is calculated, at diverse time periods (T), in the lack and existence of different Ashwagandha extract concentration. The relation between ML and T appear in Figure 1 for Ashwagandha extract. The \%IE is influenced by the AE concentration. The graphs for diverse doses of the $\mathrm{AE}$ were found below the curve of the destructive media. The ascending in $\mathrm{AE}$ concentration provides a diminishing of mass loss and the rise of aluminum corrosion inhibition. The ML results show that the Ashwagandha extract is deemed as an effective inhibitor for aluminum corrosion in one molar hydrochloric acid medium. Likewise, the surface coverage $(\Theta)$ and inhibition efficiency rise as a result of the restraint productivity because of the slight layer, established by the adsorption of AE [27]. The data obtained from ML method were recorded in table 1. 


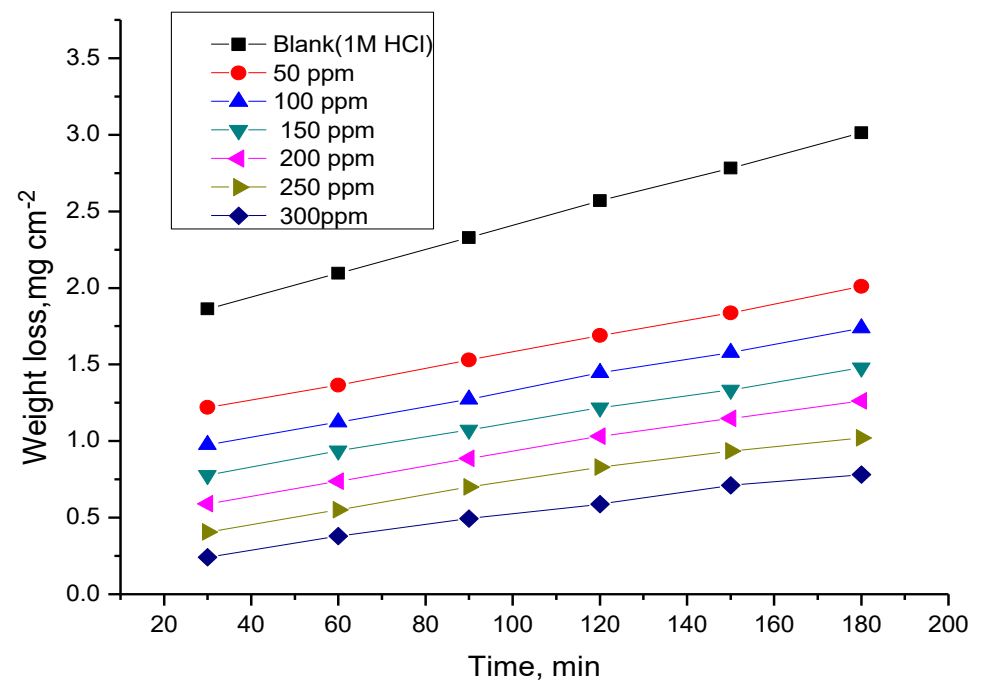

Figure 1. ML - T curve for aluminum corrosion alloy in one molar hydrochloric acid in the lack and presence of diverse concentrations of $\mathrm{AE}$ at $25^{\circ} \mathrm{C}$.

Table 1. Variety of rate of corrosion $\left(\mathrm{k}_{\text {corr }}\right)$, coverage of surface $(\theta)$, and inhibition efficiency (\%I.E) with diverse doses of Ashwagandha after 2 hours of dipping in one molar hydrochloric acid at various temperatures.

\begin{tabular}{|c|c|c|c|c|c|}
\hline Temp. ${ }^{\circ} \mathrm{C}$ & $\begin{array}{l}\text { [Inh]. } \\
\text { ppm }\end{array}$ & $\begin{array}{l}\text { Mass loss, } \\
\text { mg cm}^{-2}\end{array}$ & $\begin{array}{l}k_{\text {corr, }} \\
\text { mg cm}^{-2} \text { min }^{-1}\end{array}$ & $\boldsymbol{\theta}$ & $\%$ I.E \\
\hline \multirow[t]{7}{*}{25} & Blank & 5.21 & 0.04342 & - & - \\
\hline & 50 & 0.82 & 0.00683 & 0.843 & 84.3 \\
\hline & 100 & 0.80 & 0.00667 & 0.846 & 84.6 \\
\hline & 150 & 0.79 & 0.00658 & 0.848 & 84.8 \\
\hline & 200 & 0.75 & 0.00625 & 0.857 & 85.7 \\
\hline & 250 & 0.70 & 0.00583 & 0.865 & 86.5 \\
\hline & 300 & 0.65 & 0.00542 & 0.876 & 87.6 \\
\hline \multirow{7}{*}{30} & Blank & 14.57 & 0.12142 & - & - \\
\hline & 50 & 6.98 & 0.05817 & 0.521 & 52.1 \\
\hline & 100 & 6.94 & 0.05783 & 0.523 & 52.3 \\
\hline & 150 & 6.47 & 0.05392 & 0.556 & 55.6 \\
\hline & 200 & 5.18 & 0.04317 & 0.645 & 64.5 \\
\hline & 250 & 5.10 & 0.04250 & 0.650 & 65.0 \\
\hline & 300 & 4.82 & 0.04017 & 0.670 & 67.0 \\
\hline \multirow[t]{7}{*}{35} & Blank & 23.94 & 0.19950 & - & - \\
\hline & 50 & 13.14 & 0.10950 & 0.451 & 45.1 \\
\hline & 100 & 13.08 & 0.10900 & 0.453 & $\begin{array}{l}45.3 \\
\end{array}$ \\
\hline & 150 & 12.15 & 0.10125 & 0.492 & 49.2 \\
\hline & 200 & 9.61 & 0.08008 & 0.599 & 59.9 \\
\hline & 250 & 9.49 & 0.07908 & 0.604 & 60.4 \\
\hline & 300 & 8.99 & 0.07492 & 0.625 & 62.5 \\
\hline \multirow{7}{*}{40} & Blank & 33.31 & 0.27758 & - & - \\
\hline & 50 & 19.30 & 0.16083 & 0.421 & 42.1 \\
\hline & 100 & 19.23 & 0.16025 & 0.423 & 42.3 \\
\hline & 150 & 17.84 & 0.14867 & 0.465 & 46.5 \\
\hline & 200 & 14.04 & 0.11700 & 0.578 & 57.8 \\
\hline & 250 & 13.89 & 0.11575 & 0.583 & 58.3 \\
\hline & 300 & 13.16 & 0.10967 & 0.605 & 60.5 \\
\hline \multirow[t]{7}{*}{45} & Blank & 33.31 & 0.27758 & - & - \\
\hline & 50 & 19.30 & 0.16083 & 0.421 & 42.1 \\
\hline & 100 & 19.23 & 0.16025 & 0.423 & 42.3 \\
\hline & 150 & 17.84 & 0.14867 & 0.465 & 46.5 \\
\hline & 200 & 14.04 & 0.11700 & 0.579 & 57.9 \\
\hline & 250 & 13.89 & 0.11575 & 0.583 & 58.3 \\
\hline & 300 & 13.16 & 0.10967 & 0.605 & 60.5 \\
\hline
\end{tabular}




\subsection{PP curves.}

Figure 2 demonstrates the polarization curves for Aluminum corrosion in one molar hydrochloric acid corrosive media in the lack and attendance of diverse AE doses at room temperature. The protective percent $(\% \mathrm{IE})$ and coverage of the surface $(\theta)$ are computed from equation (4).

$$
\% \mathrm{IE}=\left[\left(\mathrm{i}^{\mathrm{o}}{ }_{\text {corr }}-\mathrm{i}_{\text {corr }}\right) / \mathrm{i}^{\mathrm{o}} \text { corr }\right] \times 100=\theta \times 100
$$

"where $\mathrm{i}^{\mathrm{o}}$ corr and $\mathrm{i}_{\text {corr }}$ are the current densities for uninhibited and inhibited samples, individually". As shown in Figure 2, both anodic and cathodic are moved to smaller current densities. Additionally, from table 2 the diminishing of $i_{\text {corr }}$ is clearly with expanding inhibitor concentration, demonstrating that the corrosion rate diminishes as a result of the adsorbed $\mathrm{AE}$ layer and protects $\mathrm{Al}$ surface from hydrochloric acid corrosion. The highest displacement in $\mathrm{E}_{\text {corr }}$ is $<85 \mathrm{mV}$, which considers that the $\mathrm{AE}$ is a mixed type inhibitor that influenced the reaction of both anodic and cathodic [28]. Moreover, the Tafel slopes are not changed, meaning that the AE is adsorbed on the metal surface and therefore hindered the corrosion process by just obstructing the active centers with no alteration in the reaction mechanism [29].

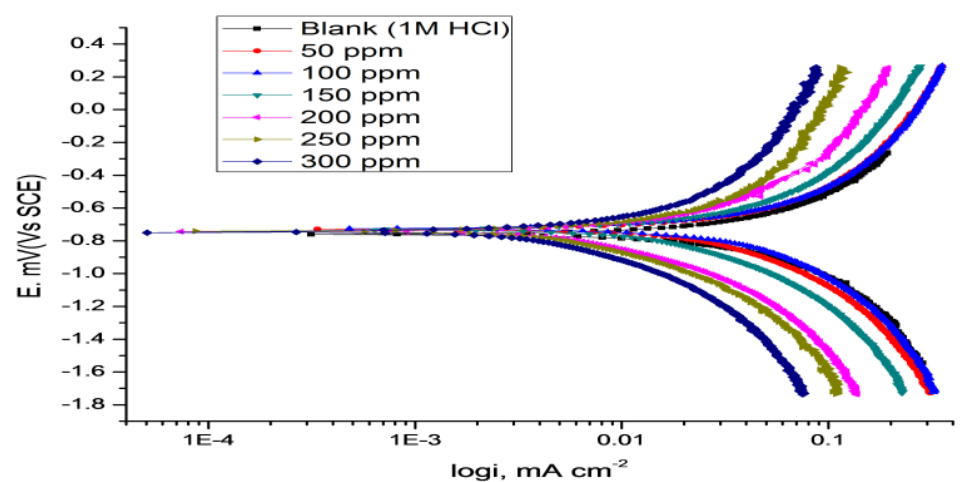

Figure 2. PP graphs for Aluminum corrosion in one molar hydrochloric acid solution in the lack and attendance of diverse doses of $\mathrm{AE}$ at room temperature.

Table 2. Potential of corrosion $\left(E_{\text {corr }}\right)$, corrosion current density $\left(i_{\text {corr }}\right)$, Tafel slopes $\left(\beta_{\mathrm{c}}, \beta_{\mathrm{a}}\right)$, surface coverage degree $(\theta)$, and inhibition efficiency (\% IE) of $\mathrm{Al}$ in one molar hydrochloric acid at room temperature $25^{\circ} \mathrm{C}$.

\begin{tabular}{|c|c|c|c|c|c|c|c|c|}
\hline Inhibitor & $\begin{array}{l}{[\mathrm{Inh}]} \\
\text { ppm }\end{array}$ & $\begin{array}{l}-E_{\text {corr }} \\
\mathrm{mV} \text { vs } \\
\text { SCE }\end{array}$ & $\begin{array}{l}\mathbf{i}_{\text {corr }} \\
\mathbf{m ~ A} \\
\mathbf{C m}^{-2}\end{array}$ & $\begin{array}{l}\beta_{\mathrm{a}} \\
\mathbf{m V} \\
\text { dec }^{-1}\end{array}$ & $\begin{array}{l}\beta_{c} \\
\mathbf{m V} \\
\operatorname{dec}^{-1}\end{array}$ & $\begin{array}{l}\text { C.Rx10 } \\
\text { mpy }\end{array}$ & $\boldsymbol{\theta}$ & IE\% \\
\hline Blank & 0 & 719 & 276 & 251 & 421 & 163 & --- & --- \\
\hline \multirow{6}{*}{$\begin{array}{l}\text { Ashwagandha } \\
\text { Extract }\end{array}$} & 50 & 722 & 137 & 152 & 172 & 59 & 0.504 & 50.4 \\
\hline & 100 & 727 & 127 & 80 & 100 & 57 & 0.540 & 54.0 \\
\hline & 150 & 729 & 82 & 60 & 100 & 37 & 0.703 & 70.3 \\
\hline & 200 & 735 & 61 & 31 & 91 & 11 & 0.779 & 77.9 \\
\hline & 250 & 737 & 55 & 22 & 92 & 5.4 & 0.801 & 80.1 \\
\hline & 300 & 739 & 31 & 33 & 93 & 4.8 & 0.888 & 88.8 \\
\hline
\end{tabular}

\subsection{Electrochemical impedance spectroscopy (EIS).}

EIS measurements were achieved to investigate the corrosion inhibition of $\mathrm{Al}$ by using $\mathrm{AE}$ after $30 \mathrm{~min}$ of dipping. Figure 3 displays the Nyquist plots for $\mathrm{Al}$ in one molar hydrochloric acid in the lack and existence of a diverse concentration of AE. The Nyquist plots revealed that each impedance diagram includes a large capacitive loop at a high frequency (HF) region and a small inductive loop at a low frequency (LF) region. The large capacitive loop is attributed to the relaxation process in the natural oxide found on the surface of the Al samples 
and its dielectric properties, while the small inductive loop is generally attributed to anodic adsorbed intermediates commanding the anodic process [30-32]. It was shown that the acquired Nyquist curves are not excellent semicircle because of frequency dispersion, and this demeanor can be ascribed to roughness and heterogeneity at the surface of the electrode [33, 34]. Moreover, the semicircular diameter of the Nyquist plot increases with raising the concentration of $\mathrm{AE}$, confirming the adsorption of $\mathrm{AE}$ on the $\mathrm{Al}$ surface, and creating a protective film.

Figure 4 demonstrates the Bode plots for $\mathrm{Al}$ in one molar hydrochloric acid in the lack and existence of a diverse concentration of AE. It was found that as the AE concentration rises. The total impedance $\mathrm{Z}$ increases as well as the phase angle shifts to more value this as a result of the adsorption of $\mathrm{AE}$ on $\mathrm{Al}$ surface [33-36].

The model of the electrical equivalent circuit has appeared in Figure 5 was utilized to show the attained impedance information. This demonstrates "the solution resistance $\left(R_{S}\right)$, the charge-transfer resistance of the interfacial corrosion reaction $\left(\mathrm{R}_{\mathrm{ct}}\right)$, the inductance $(\mathrm{L})$, the inductive resistance $\left(R_{L}\right)$, and the double-layer capacitance $\left(C_{d l}\right)$ ". A good fit with this demonstrates it was achieved by outcome information. When an inductive circle is appearing, the resistance of polarization can be computed from the subsequent eq. (5) [37]:

$$
R_{P}=\frac{R_{c t} \times R_{L}}{R_{c t}+R_{L}}
$$

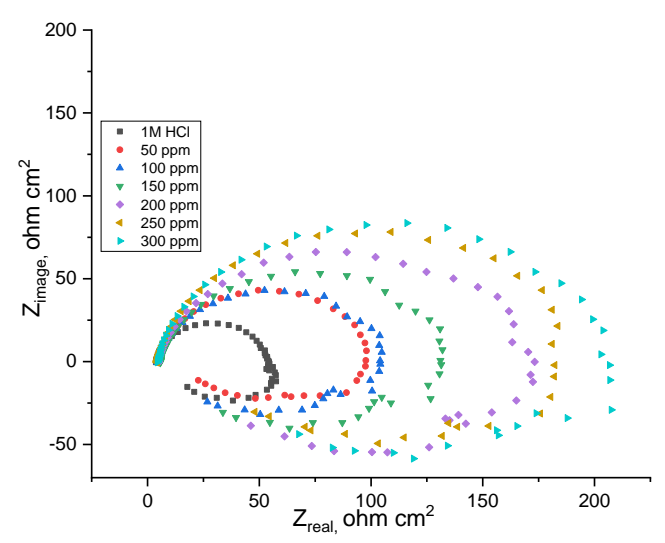

Figure 3. Nyquist plots for aluminum in one molar hydrochloric acid in the lack and attendance of diverse concentrations of $\mathrm{AE}$ at $25^{\circ} \mathrm{C}$.

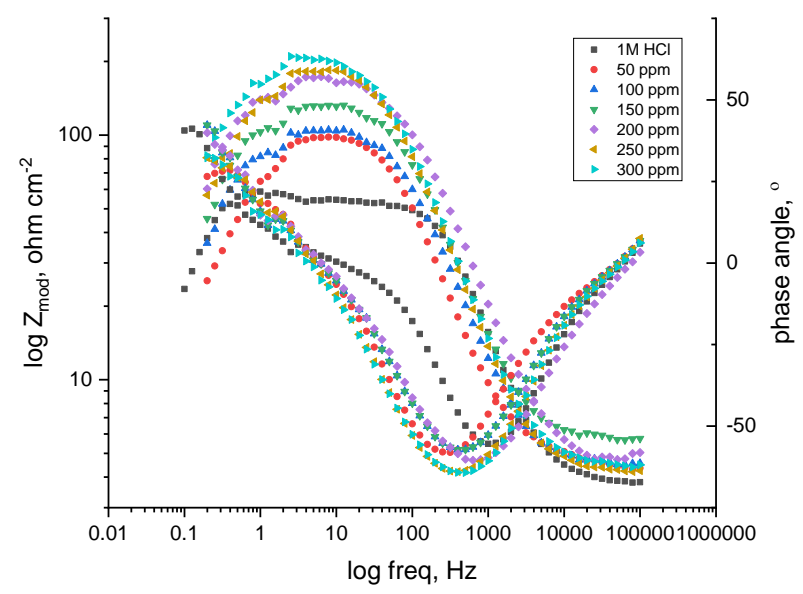

Figure 4. Bode plots for aluminum in one molar hydrochloric acid solutions in the lack and existence of diverse concentrations of $\mathrm{AE}$ at $25^{\circ} \mathrm{C}$. 


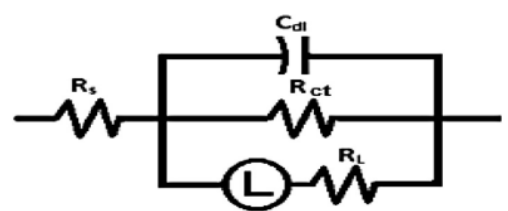

Figure 5. Electrical comparable circuit employed to fit the impedance information.

Table 3. Electrochemical kinetic parameters acquired from EIS technique for $\mathrm{Al}$ in one molar hydrochloric acid in the lack and existence of diverse concentrations of $\mathrm{AE}$ at $25^{\circ} \mathrm{C}$.

\begin{tabular}{|c|c|c|c|c|c|c|c|c|}
\hline Inhibitor & $\begin{array}{l}\text { [Inh] } \\
\text { ppm }\end{array}$ & $\begin{array}{l}R_{\mathrm{ct}} \\
\Omega \mathrm{cm}^{2}\end{array}$ & $\begin{array}{l}\mathrm{C}_{\mathrm{dl}} \\
\mu \mathrm{Fcm}^{-2}\end{array}$ & $\begin{array}{l}R_{L} \\
\Omega \mathrm{cm}^{2}\end{array}$ & $\begin{array}{l}\mathbf{R}_{\mathrm{p}}, \\
\Omega \mathrm{cm}^{2}\end{array}$ & $\begin{array}{l}\mathrm{L} \\
\mathrm{Hcm}^{-2}\end{array}$ & $\boldsymbol{\theta}$ & $\%$ IE \\
\hline Blank & 0 & 51.84 & 177.00 & 38.12 & 11.76 & 13.28 & ----- & $\begin{array}{ll}----- \\
-\end{array}$ \\
\hline \multirow[t]{6}{*}{ Ashwagandha } & 50 & 93.27 & 54.40 & 71.48 & 40.47 & 24.68 & 0.709 & 70.9 \\
\hline & 100 & 100.53 & 40.20 & 76.56 & 43.46 & 32.50 & 0.729 & 72.9 \\
\hline & 150 & 127.90 & 31.91 & 98.02 & 55.49 & 40.95 & 0.788 & 78.8 \\
\hline & 200 & 169.30 & 24.28 & 138.32 & 76.13 & 56.89 & 0.846 & 84.6 \\
\hline & 250 & 180.60 & 21.99 & 148.97 & 81.63 & 63.56 & 0.856 & 85.6 \\
\hline & 300 & 203.00 & 20.53 & 153.32 & 87.35 & 73.65 & 0.865 & 86.5 \\
\hline
\end{tabular}

EIS information Table 3 appears that the $R_{p}$ magnitudes increment and the $C_{d l}$ magnitudes diminish with the increment of the AE doses. This is often owing to the progressive substitution of $\mathrm{H}_{2} \mathrm{O}$ atoms by the adsorption of the extract atoms on the surface of the metal and diminishing the degree of the disintegration response. The large RP magnitudes are, for the most part, related to a slower corrosion system [38- 39]. The lessen inside the $\mathrm{C}_{\mathrm{dl}}$ may arise from the diminish of the adjacent dielectric constant and or from the increment of the electrical double layer thickness [40], proposing that the inhibitor molecules operate by adsorption at the metal/solution interface. The \%IE gotten from EIS method are nearby to those found from the PP measurements.

\subsection{EFM measurements.}

EFM is a secure deterioration technique that recognized the corrosion current without needing the knowledge of constants of Tafel and by just a little signal of polarization [41]. Figure 6 reveals the spectrum of EFM of $\mathrm{Al}$ in one molar hydrochloric acid solution by diverse AE concentrations. From table 4, the adding of AE with diverse doses to the destructive media lessen the corrosion current density, indicating that AE adsorbed on Al surface, forming a protective layer. The factors of causality are nearer to hypothetical magnitudes, which, as indicated by EFM hypothesis [42], ought to demonstrate the validity of the measurements. \%IE rises by raising the concentration of $\mathrm{AE}$, and it tends to be evaluated utilizing equation (5):

\subsection{Adsorption isotherm.}

An inhibitor Adsorption of on the surface of the metal has been extensively investigated by the use of adsorption isotherms. Organic molecule adsorption happens because the contact energy of the inhibitor-surface of the metal is greater than that energy of water- surface of metal $[43,45]$. For getting the adsorption isotherms, the surface coverage degree $(\theta)$ acquired from ML approach was resolved as an inhibitor function concentration (C). The magnitudes of $\theta$ were then charted to show the most appropriate adsorption model [46]. Many efforts were made to fit the experimental data to several isotherms such as "Langmuir, Frumkin, Freundlich, Temkin isotherms". The outcomes were greatest fitted by "Langmuir adsorption isotherm," as found in Figure 7 [47].

$$
\theta / 1-\theta=K_{\text {ads }} C(6)
$$


"where $\mathrm{K}_{\text {ads }}$ is the equilibrium constant of adsorption,", which attained from the "Langmuir adsorption isotherm" slope of is correlated to the adsorption free energy $\Delta \mathrm{G}^{\circ}$ ads as following:

$$
\mathrm{K}_{\mathrm{ads}}=1 / 55.5 \exp ^{-\Delta \mathrm{G}^{\circ} \text { ads } / \mathrm{RT}}
$$

"where 55.5 is the molar concentration of water in the solution in $\mathrm{M}^{-1}$ ". The values achieved are provided in Table 6.

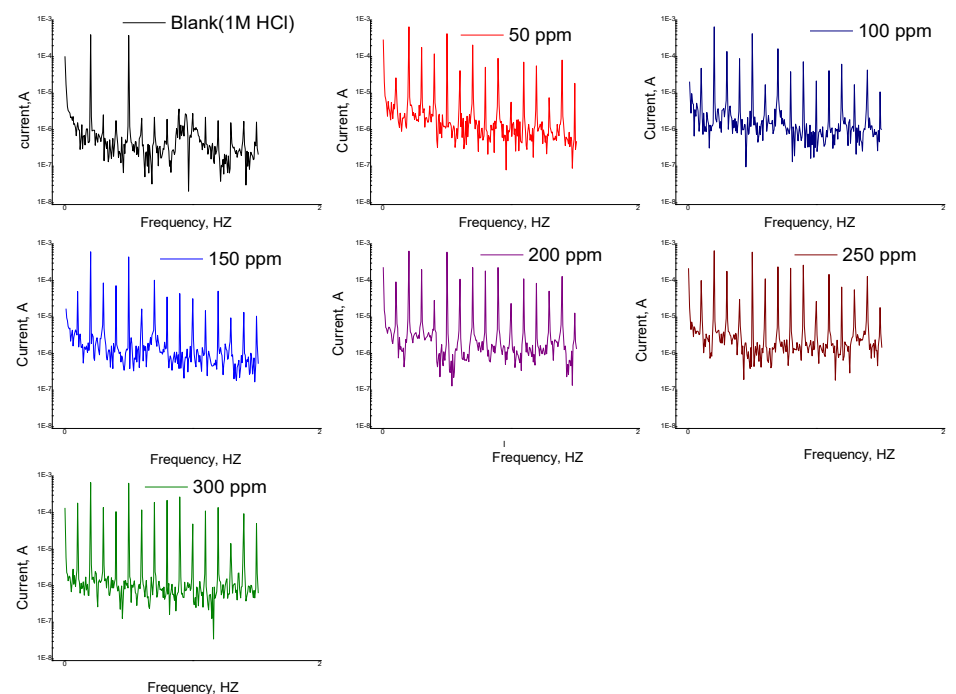

Figure 6. Intermodulation spectrums for Aluminum corrosion in one molar hydrochloric acid in the lack and attendance of diverse doses of $\mathrm{AE}$ at room temperature $25^{\circ} \mathrm{C}$.

Table 4. Electrochemical parameters were acquired from EFM technique for aluminum in one molar

\begin{tabular}{|c|c|c|c|c|c|c|c|c|c|}
\hline Inhibitor & $\begin{array}{l}\text { nyarc } \\
\text { [Inh] } \\
\text { ppm }\end{array}$ & $\begin{array}{l}\text { icorr } \\
\mathbf{m ~ A} \\
\mathbf{C m}^{-2}\end{array}$ & mV dec & 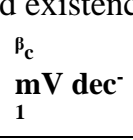 & CF-2 & $\begin{array}{l}\text { CF- } \\
3\end{array}$ & $\begin{array}{l}\text { C.Rx10 } \\
\text { mpy }\end{array}$ & $\theta$ & IE\% \\
\hline Blank & 0 & 1250 & 185 & 196 & 1.4 & 2.2 & 670 & $-\ldots$ & --- \\
\hline \multirow{6}{*}{$\begin{array}{l}\text { Ashwagandha } \\
\text { extract }\end{array}$} & 50 & 390 & 30 & 105 & 1.9 & 2.6 & 240 & 0.688 & 68.8 \\
\hline & 100 & 330 & 29 & 68 & 1.2 & 2.8 & 210 & 0.736 & 73.6 \\
\hline & 150 & 320 & 27 & 57 & 1.8 & 2.3 & 202 & 0.740 & 74.0 \\
\hline & 200 & 300 & 24 & 38 & 1.7 & 2.4 & 150 & 0.760 & 76.0 \\
\hline & 250 & 250 & 18 & 35 & 1.3 & 2.6 & 146 & 0.800 & 80.0 \\
\hline & 300 & 200 & 15 & 29 & 1.9 & 2.4 & 132 & 0.840 & 84.0 \\
\hline
\end{tabular}

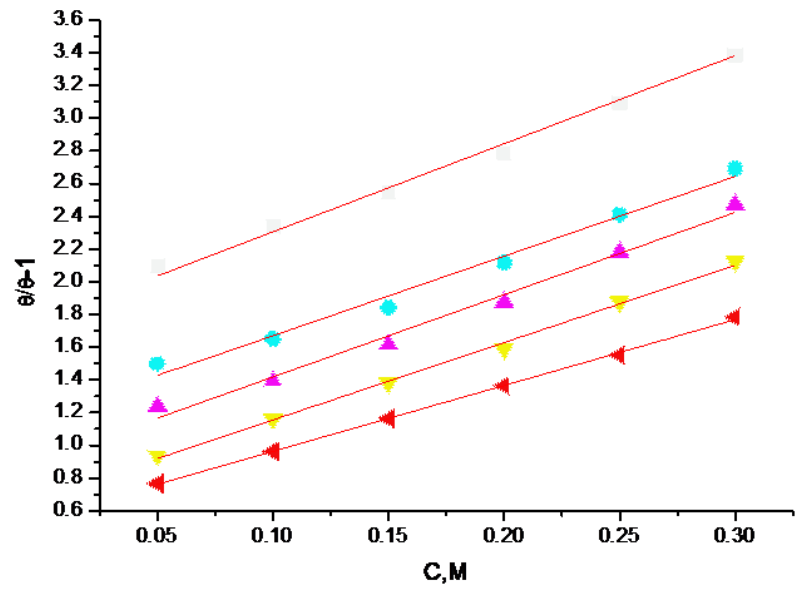

Figure 7. Curves of "Langmuir adsorption isotherm" for $\mathrm{Al}$ in one molar hydrochloric acid, including several doses of $\mathrm{AE}$ at room temperature $25^{\circ} \mathrm{C}$. 
The plot of ( $\Delta \mathrm{G}^{\mathrm{o}}$ ads $)$ vs. Time Figure 8 provided adsorption heat $\left(\Delta \mathrm{H}^{\mathrm{o}}\right.$ ads $)$ and entropy $\left(\Delta \mathrm{S}^{\mathrm{o}}\right.$ ads) based on the thermodynamic equation (8):

$$
\Delta \mathrm{G}_{\text {ads }}^{\mathrm{o}}=\Delta \mathrm{H}^{\mathrm{o}} \text { ads }-\mathrm{T} \Delta \mathrm{S}_{\text {ads }}^{\mathrm{o}}
$$

Table 5 clearly shows $\Delta \mathrm{G}^{\mathrm{o}}$ ads magnificent reliance on $\mathrm{T}$, demonstrating the great relationship between the gotten thermodynamic data. The negative $\Delta \mathrm{G}^{\mathrm{o}}$ ads sign data illustrate the spontaneity. For the most part, $\Delta \mathrm{G}^{\mathrm{o}}$ ads value equal to $-20 \mathrm{~kJ} / \mathrm{mol}$ or lesser are relating to the electrostatic interaction among the charged molecules of $\mathrm{AE}$ and the charged $\mathrm{Al}$ surface "physisorption", but those equal to $-40 \mathrm{~kJ} / \mathrm{mol}$ or greater are conforming to the charge exchange or transmission from $\mathrm{AE}$ molecules to the $\mathrm{Al}$ surface in order to create a coordinate kind of bond "chemisorption" [48] The adsorption was built up to be physical from the given data of $\Delta \mathrm{G}^{\mathrm{o}}$ ads. Endothermic adsorption process $\left(\Delta \mathrm{H}^{\mathrm{o}}\right.$ ads $\left.>0\right)$ promotions depend obviously on chemisorption [49], an exothermic process $\left(\Delta \mathrm{H}^{\mathrm{o}}\right.$ ads $\left.<0\right)$ may contain either chemisorption or physisorption or a mix of both types. The determined $\Delta \mathrm{H}^{\mathrm{o}}$ ads values in the present for Ashwagandha adsorption in acidic solution, demonstrating that this inhibitor may adsorb chemically on $\mathrm{Al}$ surface. The sign of $\Delta \mathrm{S}^{\mathrm{o}}$ ads in the existence of the $\mathrm{AE}$ is negative, which shows that it diminishing in a disorder of corrosion process on $\mathrm{Al}$ surface [50].

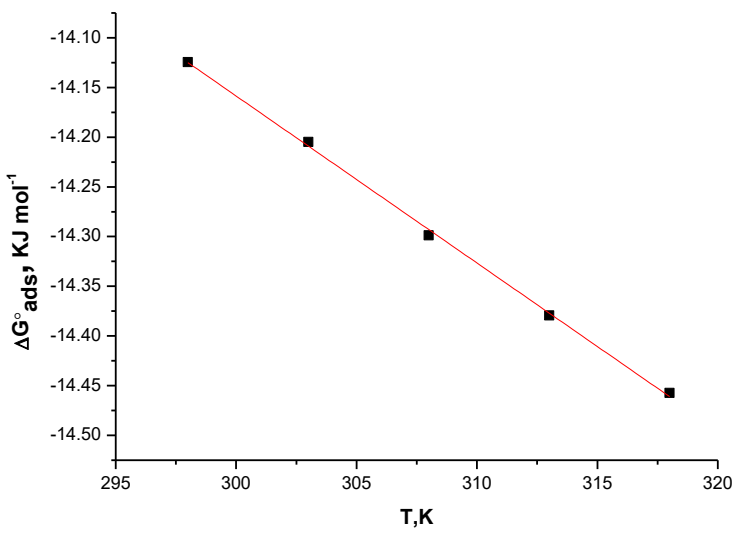

Figure 8. The Variety of $\Delta \mathrm{G}^{\mathrm{o}}$ ads vs. Time for AE adsorption on $\mathrm{Al}$ surface in one molar hydrochloric acid at various temperatures.

Table 5. Adsorption thermodynamic parameters for the AE on Aluminum surface in one molar hydrochloric acid at various temperatures.

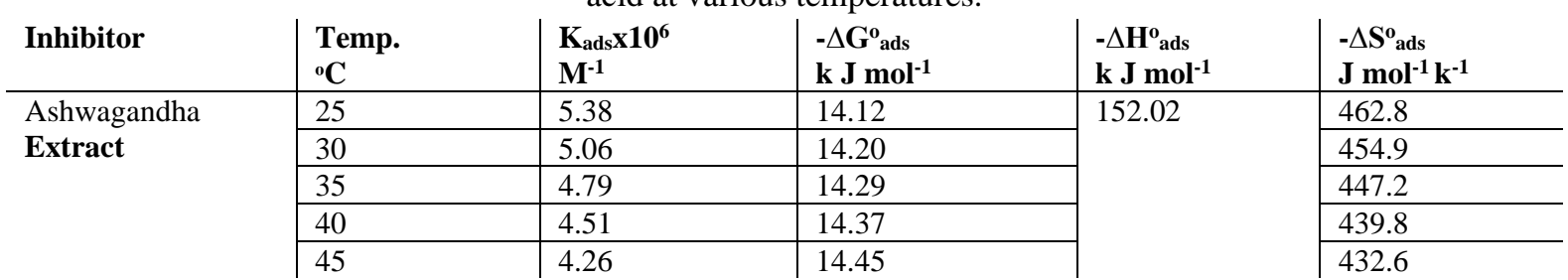

3.6. The corrosion thermodynamic parameters.

At various temperatures $\left(25-45^{\circ} \mathrm{C}\right)$, ML method was accomplished in the existence of diverse concentrations of $\mathrm{AE}$. It has been discovered that the corrosion rate is directly comparable to the temperature table 1 , which makes \%IE diminishes with temperature. The corrosion parameter with and without $\mathrm{AE}$ in the temperature variety $25^{\circ} \mathrm{C}-45^{\circ} \mathrm{C}$ has been summarized in Table 1. The activation energy ( $\left.\mathrm{Ea}^{*}\right)$ for dissolution of $\mathrm{Al}$ alloy in $1.0 \mathrm{M}$ hydrochloric acid was measured by utilizing the Arrhenius equation from the slope of plots as follows: 


$$
\log k=\frac{-E_{a}^{*}}{2.303 R T}+\log A
$$

"where the rate of corrosion is expressed by $\mathrm{k}$ and A is the Arrhenius pre-exponential factor".

The values of $\mathrm{E}_{\mathrm{a}}{ }^{*}$ compute from the plotting of $\log \mathrm{k}_{\text {corr }}$ versus temperature are demonstrated in Figure 9. The values of $\mathrm{E}_{\mathrm{a}}{ }^{*}$ for $\mathrm{Al}$ in one molar hydrochloric acid ascend with increasing AE concentration. Hence, we can induce that the attendance of the AE generates an energy barrier for the reaction of corrosion, and this barrier rises with raising the extract concentration. Thus, the protection performance of the extract diminishes noticeably with rising temperatures. This result designates that the adsorption of $\mathrm{AE}$ molecules on the $\mathrm{Al}$ alloy surface is physisorption [51]. The entropy change $\left(\Delta \mathrm{S}^{*}\right)$ and the enthalpy change $\left(\Delta \mathrm{H}^{*}\right)$ can be computed as follows:

$$
k=\left(\frac{R T}{N h}\right) \exp \left(\frac{\Delta S^{*}}{R}\right) \exp \left(\frac{\Delta H^{*}}{R T}\right)
$$

"where $\mathrm{k}$ is the rate of corrosion, $\mathrm{h}$ is Planck's constant, $\mathrm{N}$ is Avogadro number, $\Delta \mathrm{S}^{*}$ is the entropy of activation, and $\Delta \mathrm{H}^{*}$ is the enthalpy of activation". $\log (\mathrm{k} / \mathrm{T})$ vs. $1 / \mathrm{T}$ plot Figure 10 ought to provide a straight line, by using a slope of $\left(\Delta \mathrm{H}^{*} / 2.303 \mathrm{R}\right)$ and an intercept of $[\log$ $\left.(\mathrm{R} / \mathrm{Nh})+\Delta \mathrm{S}^{*} / 2.303 \mathrm{R}\right]$, can calculate magnitudes of $\Delta \mathrm{S}^{*}$ and $\Delta \mathrm{H}^{*}$ can be determined Table 6 . $\Delta \mathrm{S}^{*}$ magnitudes are negative, demonstrating that the activated complex in the rate-determining step shows more association in contrast with the dissociation step [52]. The sign of $\Delta \mathrm{H}^{*}$ is $(+\mathrm{ve})$ that shows that inhibitor molecules the adsorption is an endothermic process. Usually, an endothermic process signifies the chemisorption process.

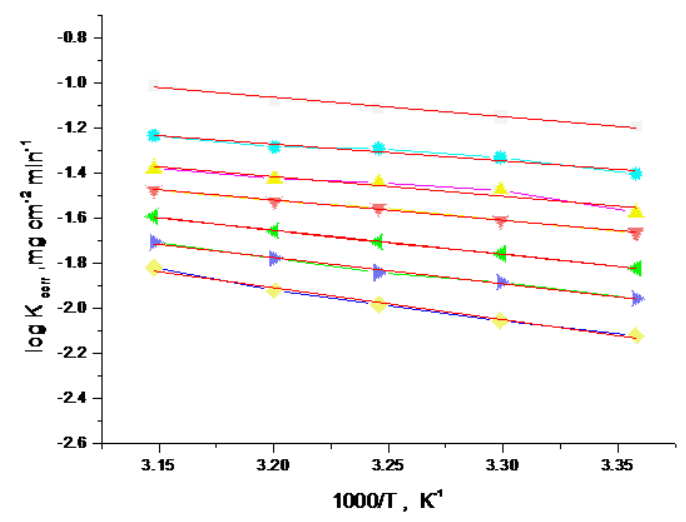

Figure 9. Arrhenius plots for aluminum corrosion rates $\left(\mathrm{k}_{\text {corr }}\right)$ after 120 minutes of dipping in one molar hydrochloric acid with and without different concentrations Ashwagandha extract.

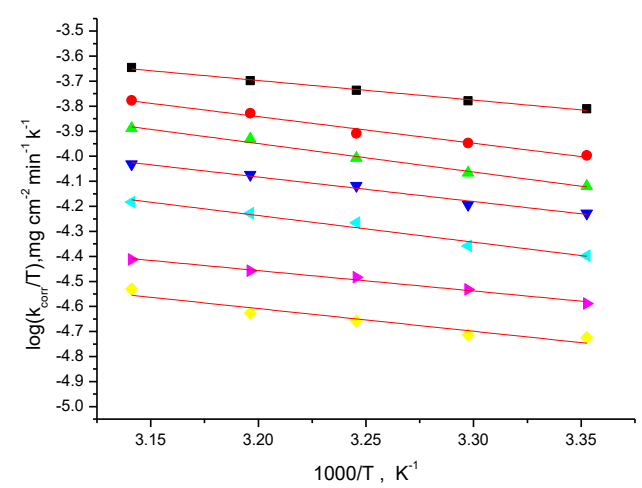

Figure 10. Transition-state for aluminum corrosion in one molar hydrochloric acid with and without diverse concentrations of Ashwagandha extract. 
Table 6. The parameters of thermodynamic activation for Al corrosion in the lack and existence of diverse doses of $\mathrm{AE}$ in one molar hydrochloric acid.

\begin{tabular}{|c|c|c|c|}
\hline $\begin{array}{l}\text { Conc. } \\
\text { ppm }\end{array}$ & $\begin{array}{c}\mathbf{E a}^{*}, \\
\mathrm{~kJ} \mathrm{~mol}^{-1}\end{array}$ & $\underset{\text { kJ mol }}{\Delta \mathbf{H}^{-1}}$ & $\begin{array}{c}-\Delta \mathbf{S}^{*}, \\
\mathbf{J} \mathbf{~ m o l}^{-1} \mathbf{K}^{-1}\end{array}$ \\
\hline Blank & 35.5 & 38.2 & 160.1 \\
\hline 50 & 23.1 & 42.7 & 121.0 \\
\hline 100 & 30.4 & 47.4 & 110.9 \\
\hline 150 & 29.5 & 50.1 & 105.6 \\
\hline 200 & 39.3 & 48.7 & 114.4 \\
\hline 250 & 46.2 & 47.0 & 124.3 \\
\hline 300 & 46.4 & 45.9 & 131.6 \\
\hline
\end{tabular}

\subsection{AFM analysis.}

AFM is a significant examination for determining the metal surface roughness at the highest resolution in nanometer fractions [53]. This technique can give insights regarding the shape of the surface of $\mathrm{Al}$, which is helpful in corrosion science research. AFM photos with three-dimensional (3D) are presented in Figure 11. the average roughness $\left(R_{a}\right)$ is shown in Table 7. A proportional view of relative perspective on Table 7 obviously reveals that the surface of the metal prior to immersion in one molar hydrochloric acid is smoothened (46.4 $\mathrm{nm}$ ), afterward immersion one molar hydrochloric acid, the surface is destroyed, and the roughness increases $(760.0 \mathrm{~nm})$ while the Al samples treated with $300 \mathrm{ppm}$ AE the surface become smoother and the roughness decreased $(410.9 \mathrm{~nm})$ in comparison with a blank sample as a consequence of the adsorption of $\mathrm{AE}$ on the surface of $\mathrm{Al}$ metal forming a protective film.

Table 7. AFM roughness data of Ashwagandha at $300 \mathrm{ppm}$ for 24 hours at $25^{\circ} \mathrm{C}$.

\begin{tabular}{l|l} 
Specimen & Average roughness $\left(\mathbf{R}_{\mathbf{a}}\right) \mathbf{~ n m}$ \\
\hline $\mathrm{Al}$ surface (free) & 46.4 \\
\hline $\mathrm{Al}$ in $1 \mathrm{M} \mathrm{HCl}$ (blank) & 760.0 \\
\hline $\mathrm{Al}$ in $1 \mathrm{M} \mathrm{HCl}+300 \mathrm{ppm} \mathrm{AE}$ & 410.9
\end{tabular}
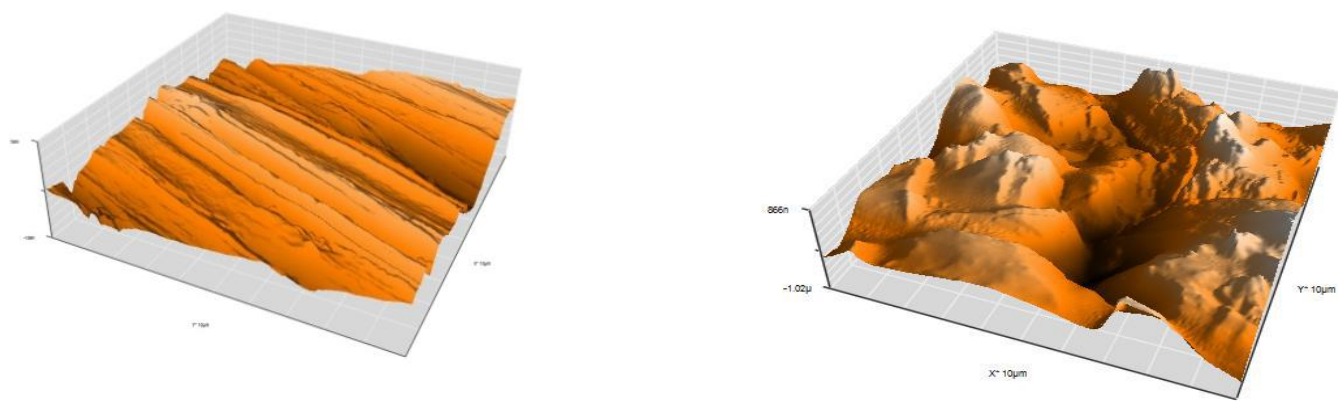

(free)

(Blank)

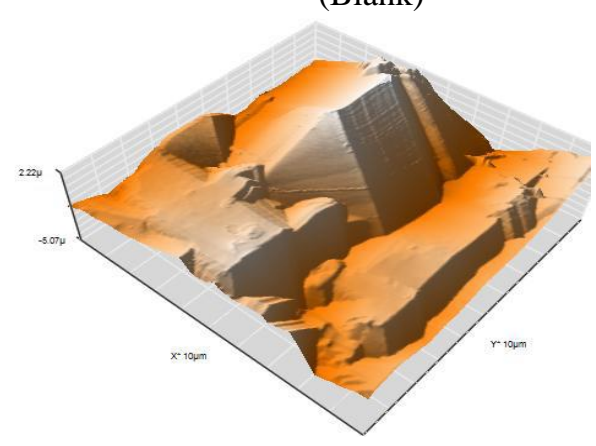

(Inhibited)

Figure 11. Three-dimensional (3D) AFM images Al metal before dipping in one molar hydrochloric acid (free) and after dipping in one molar hydrochloric acid in the lack (blank) and attendance of $300 \mathrm{ppm}$ of $\mathrm{AE}$ (inhibited) for 24 hours at $25^{\circ} \mathrm{C}$. 


\subsection{XPS technique.}

XPS analysis gets profound knowledge approximately the chemical nature of the interface among the AE and the surface of Al. This spectrum acquired for aluminum surface, subsequently soaking in one molar hydrochloric acid solution containing $300 \mathrm{ppm}$ of AE for 24 hours. The XPS deconvoluted profiles of $\mathrm{Al} 2 \mathrm{p}, \mathrm{O} 1 \mathrm{~s}, \mathrm{Cl} 2 \mathrm{p}$, and $\mathrm{C} 1 \mathrm{~s}$ appeared in Figure 12. The Al 2p spectra demonstrated at binding energy (BE) of $74.47 \mathrm{eV}$ Figure 12a may be ascribed for aluminum oxide $\left(\mathrm{Al}_{2} \mathrm{O}_{3}\right)$. [54-55]. The spectrum of $\mathrm{O} 1 \mathrm{~s}$ Figure 12b is consisted of three peaks, at 530.86, $531.99 \mathrm{eV}$, which appointed to $\mathrm{Al}-\mathrm{O}-\mathrm{Al}$ bonds (oxide) in $\mathrm{Al}_{2} \mathrm{O}_{3}$ [54] and at $532.98 \mathrm{eV}$ binding energy, which associated to $\mathrm{Al}-\mathrm{OH}$ bond (hydroxide) in $\mathrm{Al}(\mathrm{OH})_{3}$ [56]. The $\mathrm{Cl} 2 \mathrm{p}$ is included 2 peaks situated at $197.81 \mathrm{eV}$ for $\mathrm{Cl} 2 \mathrm{p}_{3 / 2}$ and $199.46 \mathrm{eV}$ for $\mathrm{Cl} 2 \mathrm{p}_{1 / 2}$ Figure 12 c [57]. The C1s spectra represented three peaks found at 284.40, 285.93, $288.90 \mathrm{eV}$ Figure 12d. The greatest peak at 284.40 can be ascribed to the $\mathrm{C}-\mathrm{C}, \mathrm{C}-\mathrm{H}, \mathrm{C}=\mathrm{C}$ bond of aromatic rings. Additionally, the peaks placed at $285.93 \mathrm{eV}$ are ascribed to the C-O-C, C-O bonds, individually [58]. The peak found at $288.90 \mathrm{eV}$, which is attributed to $\mathrm{O}-\mathrm{C}=\mathrm{O}, \mathrm{C}=\mathrm{O}$ appears that the molecules of AE have been arranged and adsorbed on the surface of Al [59]. Lastly, the XPS spectra demonstrated that the protective film created on the surface involves a mix of components, including Carbon and Oxygen atoms, that demonstrate the establishment of the inhibitive layer of the $\mathrm{AE}$.

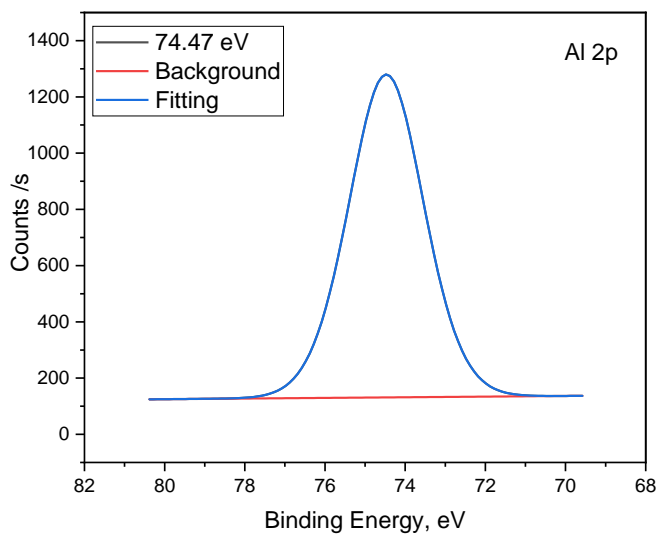

(a)

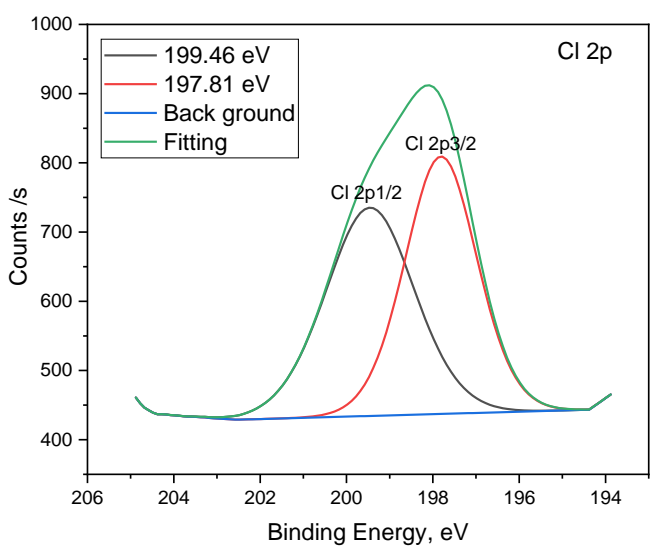

(c)

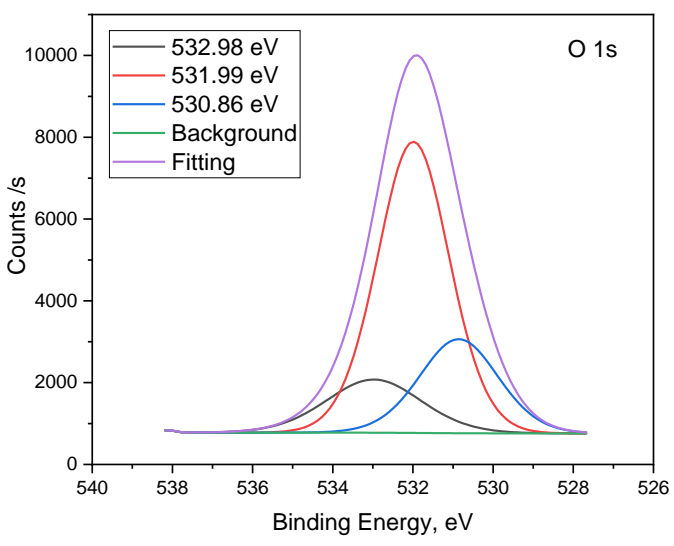

(b)

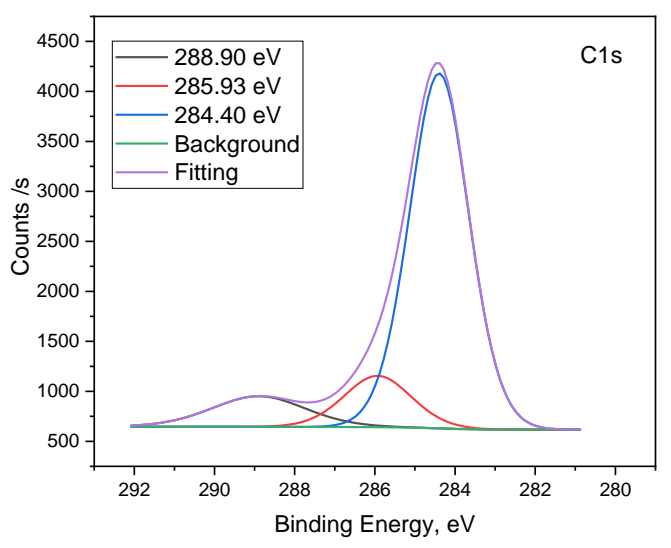

(d)

Figure 12. XPS deconvoluted profiles of (a) Al 2p, (b) Oxygen 1s, (c) Chlorine 2p, and (d) Carbon 1s, for aluminum in one molar hydrochloric acid containing $300 \mathrm{pm} \mathrm{AE}$. 


\subsection{Mechanism of the corrosion inhibition.}

In accordance with chemical and electrochemical measurements, the adding of AE prompts impeding aluminum corrosion. From the outcomes, the inhibition mechanism involving the hindering of surface-active sites that adsorbed the AE. AE adsorption mechanism includes physisorption. According to the values of $\Delta \mathrm{G}^{\mathrm{o}}$ ads around $14 \mathrm{~kJ} \mathrm{~mol}^{-1}$, and this occurs via the electrostatic attraction between negative charge $\mathrm{Al}$ surfaces and the positive charge of the protonated component in AE [50]. The inhibitory abilities of these constituents may be attributed to their adsorption by means of the $-\mathrm{NH}, \mathrm{C}=\mathrm{O}, \mathrm{OH}$, etc. groups, in addition, the existence of $\pi$-electrons in benzene rings. These organic molecules acquire adsorption at the surface of $\mathrm{Al}$ creating an insurance layer that protects the $\mathrm{Al}$ surfaces [60].

\section{Conclusions}

Ashwagandha extract has well corrosion inhibiting action on aluminum in one molar hydrochloric acid as affirmed by chemical, electrochemical, and surface analysis. PP results demonstrated that the $\mathrm{AE}$ hindered both anodic and cathodic reactions (i.e., mixed type inhibitor). \% I.E. of $\mathrm{AE}$ diminished with temperature ascending. The adsorption of $\mathrm{AE}$ complies with the Langmuir isotherm and is considered as physisorption. AFM and XPS analysis give information about morphology, the roughness of the $\mathrm{Al}$ surfaces, and the chemical nature between $\mathrm{AE}$ and $\mathrm{Al}$ surface; hence, they confirm the adsorption of $\mathrm{AE}$ on $\mathrm{Al}$ surface. There is a good accord between chemical and electrochemical measurements.

\section{Funding}

This research received no external funding.

\section{Acknowledgments}

This research has no acknowledgment.

\section{Conflicts of Interest}

The authors declare no conflict of interest.

\section{References}

1. Singh, A.; Ansari, K.R.; Chauhan, D.S.; Quraishi, M.A.; Lgaz, H.; Chung, I.-M. Comprehensive investigation of steel corrosion inhibition at macro/micro level by ecofriendly green corrosion inhibitor in $15 \% \mathrm{HCl}$ medium. Journal of Colloid and Interface Science 2020, 560, 225-236, https://doi.org/10.1016/j.jcis.2019.10.040.

2. Njoku, D.I.; Li, Y.; Lgaz, H.; Oguzie, E.E. Dispersive adsorption of Xylopia aethiopica constituents on carbon steel in acid-chloride medium: A combined experimental and theoretical approach. Journal of Molecular Liquids 2018, 249, 371-388, https://doi.org/10.1016/j.molliq.2017.11.051.

3. Gupta, R.K.; Malviya, M.; Ansari, K.R.; Lgaz, H.; Chauhan, D.S.; Quraishi, M.A. Functionalized graphene oxide as a new generation corrosion inhibitor for industrial pickling process: DFT and experimental approach. Materials Chemistry and Physics 2019, https://doi.org/10.1016/j.matchemphys.2019.121727.

4. Liu, Y.; Zou, C.; Yan, X.; Xiao, R.; Wang, T.; Li, M. $\beta$-Cyclodextrin Modified Natural Chitosan as a Green Inhibitor for Carbon Steel in Acid Solutions. Industrial \& Engineering Chemistry Research 2015, 54, 56645672, https://doi.org/10.1021/acs.iecr.5b00930.

5. Tourabi, M.; Nohair, K.; Traisnel, M.; Jama, C.; Bentiss, F. Electrochemical and XPS studies of the corrosion inhibition of carbon steel in hydrochloric acid pickling solutions by 3,5-bis(2-thienylmethyl)-4-amino-1,2,4triazole. Corrosion Science 2013, 75, 123-133, https://doi.org/10.1016/j.corsci.2013.05.023. 
6. Bashir, S.; Sharma, V.; Lgaz, H.; Chung, I.-M.; Singh, A.; Kumar, A. The inhibition action of analgin on the corrosion of mild steel in acidic medium: A combined theoretical and experimental approach. Journal of Molecular Liquids 2018, 263, 454-462, https://doi.org/10.1016/j.molliq.2018.04.143.

7. Singh, A.; Pramanik, T., Kumar, A., Gupta, M. Phenobarbital: a new and effective corrosion inhibitor for mild steel in $1 \mathrm{M} \mathrm{HCl}$ Solution. Asian J. Chem. 2013, 25, 9808-9812, https://doi.org/10.14233/ajchem.2013.15414.

8. Bashir, S.; Lgaz, H.; Chung, I.I.I.M.; Kumar, A. Potential of Venlafaxine in the inhibition of mild steel corrosion in $\mathrm{HCl}$ : insights from experimental and computational studies. Chemical Papers 2019, 73, 22552264, https://doi.org/10.1007/s11696-019-00775-0.

9. Migahed, M.A.; Azzam, E.M.S.; Al-Sabagh, A.M. Corrosion inhibition of mild steel in 1 M sulfuric acid solution using anionic surfactant. Materials Chemistry and Physics 2004, 85, 273-279, http://dx.doi.org/10.1016/j.matchemphys.2003.12.027

10. Tan, B.; Zhang, S.; Qiang, Y.; Guo, L.; Feng, L.; Liao, C.; Xu, Y.; Chen, S. A combined experimental and theoretical study of the inhibition effect of three disulfide-based flavouring agents for copper corrosion in $0.5 \mathrm{M}$ sulfuric acid. Journal of Colloid and Interface Science 2018, 526, 268-280, http://dx.doi.org/10.1016/j.jcis.2018.04.092

11. Bashir, S.; Singh, G.; Kumar, A. An Investigation on Mitigation of Corrosion of Aluminium by Origanum Vulgare in Acidic Medium. Protection of Metals and Physical Chemistry of Surfaces 2018, 54, 148-152, https://doi.org/10.1134/S2070205118010185.

12. Bashir, S.; Singh, G.; Kumar, A. Shatavari (Asparagus Racemosus) as green corrosion inhibitor of aluminium in acidic medium. J. Mater. Environ. Sci. 2017, 8, 4284-4291, http://dx.doi.org/10.26872/jmes.2017.8.12.451.

13. Shalabi, K.; Abdallah, Y.M.; Fouda, A.S. Corrosion inhibition of aluminum in $0.5 \mathrm{M} \mathrm{HCl}$ solutions containing phenyl sulfonylacetophenoneazo derivatives. Research on Chemical Intermediates 2015, 41, 4687-4711, https://doi.org/10.1007/s11164-014-1561-5.

14. Guruprasad, A.M.; Sachin, H.P.; Swetha, G.A.; Prasanna, B.M. Corrosion inhibition of zinc in $0.1 \mathrm{M}$ hydrochloric acid medium with clotrimazole: Experimental, theoretical and quantum studies. Surfaces and Interfaces 2020, 19, https://doi.org/10.1016/j.surfin.2020.100478.

15. Branzoi, V.; Golgovici, F.; Branzoi, F. Aluminium corrosion in hydrochloric acid solutions and the effect of some organic inhibitors. Materials Chemistry and Physics 2003, 78, 122-131, http://dx.doi.org/10.1016/s0254-0584(02)00222-5.

16. Okafor, P.C.; Zheng, Y. Synergistic inhibition behaviour of methylbenzyl quaternary imidazoline derivative and iodide ions on mild steel in H2SO4 solutions. Corrosion Science 2009, 51, 850-859, https://doi.org/10.1016/j.corsci.2009.01.027.

17. Abdallah, Y.M.; Shalabi, K.; Bayoumy, N.M. Eco-friendly synthesis, biological activity and evaluation of some new pyridopyrimidinone derivatives as corrosion inhibitors for API 5L X52 carbon steel in 5\% sulfamic acid medium. Journal of Molecular Structure 2018, 1171, 658-671, https://doi.org/10.1016/j.molstruc.2018.06.045.

18. Ali, A.I.; Foaud, N. Inhibition of aluminum corrosion in hydrochloric acid solution using black mulberry extract. Journal of Materials and Environmental Science 2012, 3, 917-924.

19. Nwosu, F.O.; Owate, I.O.; Osarolube, E. Acidic Corrosion Inhibition Mechanism of Aluminum Alloy Using Green Inhibitors. American Journal of Materials Science 2018, 8, 45-50.

20. Iroha, N.; Akaranta, O.; James, A. Red Onion Skin Extract-formaldehyde Resin as Corrosion Inhibitor for Mild Steel in Hydrochloric Acid Solution. International Research Journal of Pure and Applied Chemistry 2015, 6, 174-181, https://doi.org/10.9734/irjpac/2015/9555.

21. Chaurasiya, N.D.; Uniyal, G.C.; Lal, P.; Misra, L.; Sangwan, N.S.; Tuli, R.; Sangwan, R.S. Analysis of withanolides in root and leaf of Withania somnifera by HPLC with photodiode array and evaporative light scattering detection. Phytochemical Analysis 2008, 19, 148-154, https://doi.org/10.1002/pca.1029.

22. Singh, N.; Bhalla, M.; de Jager, P.; Gilca, M. An overview on Ashwagandha: a Rasayana (rejuvenator) of Ayurveda. Afr J Tradit Complement Altern Med 2011, 8, 208-213, https://doi.org/10.4314/ajtcam.v8i5S.9.

23. Abdel-Gaber, A.M.; Abd-El-Nabey, B.A.; Khamis, E.; Abd-El-Khalek, D.E. A natural extract as scale and corrosion inhibitor for steel surface in brine solution. Desalination 2011, 278, 337-342, https://doi.org/10.1016/j.desal.2011.05.048.

24. Shalabi, K.; Helmy, A.M.; El-Askalany, A.H.; Shahba, M.M. New pyridinium bromide mono-cationic surfactant as corrosion inhibitor for carbon steel during chemical cleaning: Experimental and theoretical studies. Journal of Molecular Liquids 2019, 293, https://doi.org/10.1016/j.molliq.2019.111480.

25. Abdallah, M.; Gad, E.A.M.; Sobhi, M.; Al-Fahemi, J.H.; Alfakeer, M.M. Performance of tramadol drug as a safe inhibitor for aluminum corrosion in $1.0 \mathrm{M} \mathrm{HCl}$ solution and understanding mechanism of inhibition using DFT. Egyptian Journal of Petroleum 2019, 28, 173-181, https://doi.org/10.1016/j.ejpe.2019.02.003.

26. Shahabi, S.; Hamidi, S.; Ghasemi, J.B.; Norouzi, P.; Shakeri, A. Synthesis, experimental, quantum chemical and molecular dynamics study of carbon steel corrosion inhibition effect of two Schiff bases in $\mathrm{HCl}$ solution. Journal of Molecular Liquids 2019, 285, 626-639, https://doi.org/10.1016/j.molliq.2019.04.137. 
27. Obot, I.B.; Obi-Egbedi, N.O. Fluconazole as an inhibitor for aluminium corrosion in 0.1M HCl. Colloids and Surfaces A: Physicochemical and Engineering Aspects 2008, 330, 207-212, https://doi.org/10.1016/j.colsurfa.2008.07.058.

28. Fouda, A.S.; El Morsi, M.A.; El Mogy, T. Studies on the inhibition of carbon steel corrosion in hydrochloric acid solution by expired Carvedilol drug. Green Chemistry Letters and Reviews 2017, 10, 336-345, https://doi.org/10.1080/17518253.2017.1380236.

29. Bosch, R.W.; Hubrecht, J.; Bogaerts, W.F.; Syrett, B.C. Electrochemical Frequency Modulation: A New Electrochemical Technique for Online Corrosion Monitoring. CORROSION 2001, 57, 60-70, https://doi.org/10.5006/1.3290331.

30. Zhang, D.-Q.; Cai, Q.-R.; He, X.-M.; Gao, L.-X.; Kim, G.S. Corrosion inhibition and adsorption behavior of methionine on copper in $\mathrm{HCl}$ and synergistic effect of zinc ions. Materials Chemistry and Physics 2009 , 114, 612-617, https://doi.org/10.1016/j.matchemphys.2008.10.007.

31. Yousefi, A.; Javadian, S.; Dalir, N.; Kakemam, J.; Akbari, J. Imidazolium-based ionic liquids as modulators of corrosion inhibition of SDS on mild steel in hydrochloric acid solutions: experimental and theoretical studies. RSC Advances 2015, 5, 11697-11713, https://doi.org/10.1039/C4RA10995C.

32. Tao, Z.; Zhang, S.; Li, W.; Hou, B. Corrosion inhibition of mild steel in acidic solution by some oxo-triazole derivatives. Corrosion Science 2009, 51, 2588-2595, https://doi.org/10.1016/j.corsci.2009.06.042.

33. Ferreira, E.S.; Giacomelli, C.; Giacomelli, F.C.; Spinelli, A. Evaluation of the inhibitor effect of 1-ascorbic acid on the corrosion of mild steel. Materials Chemistry and Physics 2004, 83, 129-134, https://doi.org/10.1016/j.matchemphys.2003.09.020.

34. Abdallah, M.; Al-abdali, F.H.; Kamar, E.M.; El-Sayed, R.; Abdel Hameed, R.S. Corrosion inhibition of aluminum in $1.0 \mathrm{M} \mathrm{HCl}$ solution by some nonionic surfactant compounds containing five membered heterocyclic moiety. Chemical Data Collections 2020, 28, 100407-100415, https://doi.org/10.1016/j.cdc.2020.100407.

35. Bashir, S.; Thakur, A.; Lgaz, H.; Chung, I.-M.; Kumar, A. Corrosion inhibition efficiency of bronopol on aluminium in $0.5 \mathrm{M} \mathrm{HCl}$ solution: Insights from experimental and quantum chemical studies. Surfaces and Interfaces 2020, 20, https://doi.org/10.1016/j.surfin.2020.100542.

36. Abdel-Rehim, S.S.; Khaled, K.F.; Abd-Elshafi, N.S. Electrochemical frequency modulation as a new technique for monitoring corrosion inhibition of iron in acid media by new thiourea derivative. Electrochimica Acta 2006, 51, 3269-3277, https://doi.org/10.1016/j.electacta.2005.09.018.

37. Padash, R.; Sajadi, G.S.; Jafari, A.H.; Jamalizadeh, E.; Rad, A.S. Corrosion control of aluminum in the solutions of $\mathrm{NaCl}, \mathrm{HCl}$ and $\mathrm{NaOH}$ using 2,6-dimethylpyridine inhibitor: Experimental and DFT insights.

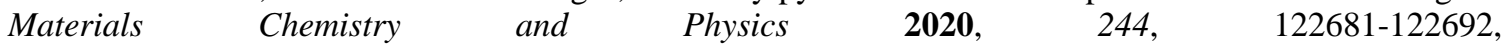
https://doi.org/10.1016/j.matchemphys.2020.122681.

38. Pandey, V.; Singh, J.K.; Chattopadhyay, K.; Srinivas, N.C.S.; Singh, V. Optimization of USSP duration for enhanced corrosion resistance of AA7075. Ultrasonics 2019, 91, 180-192, https://doi.org/10.1016/j.ultras.2018.08.011.

39. Chaubey, N.; Singh, V.K.; Quraishi, M.A. Papaya peel extract as potential corrosion inhibitor for Aluminium alloy in 1M HCl: Electrochemical and quantum chemical study. Ain Shams Engineering Journal 2018, 9, 1131-1140, https://doi.org/10.1016/j.asej.2016.04.010.

40. Li, X.; Deng, S.; Xie, X. Experimental and theoretical study on corrosion inhibition of o-phenanthroline for aluminum in $\mathrm{HCl}$ solution. Journal of the Taiwan Institute of Chemical Engineers 2014, 45, 1865-1875, https://doi.org/10.1016/j.jtice.2013.10.007.

41. Eid, A.M.; Shaaban, S.; Shalabi, K. Tetrazole-based organoselenium bi-functionalized corrosion inhibitors during oil well acidizing: Experimental, computational studies, and SRB bioassay. Journal of Molecular Liquids 2020, 298, 111980-111994, https://doi.org/10.1016/j.molliq.2019.111980.

42. Shalabi, K.; Nazeer, A.A. Ethoxylates nonionic surfactants as promising environmentally safe inhibitors for corrosion protection of reinforcing steel in $3.5 \% \mathrm{NaCl}$ saturated with $\mathrm{Ca}(\mathrm{OH}) 2$ solution. Journal of Molecular Structure 2019, 1195, 863-876, https://doi.org/10.1016/j.molstruc.2019.06.033.

43. Li, X.-H.; Deng, S.-D.; Fu, H. Inhibition by Jasminum nudiflorum Lindl. leaves extract of the corrosion of cold rolled steel in hydrochloric acid solution. Journal of Applied Electrochemistry 2010, 40, 1641-1649, https://doi.org/10.1007/s10800-010-0151-5.

44. Lagrenée, M.; Mernari, B.; Bouanis, M.; Traisnel, M.; Bentiss, F. Study of the mechanism and inhibiting efficiency of 3,5-bis(4-methylthiophenyl)-4H-1,2,4-triazole on mild steel corrosion in acidic media. Corrosion Science 2002, 44, 573-588, https://doi.org/10.1016/S0010-938X(01)00075-0.

45. Kuş, E.; Mansfeld, F. An evaluation of the electrochemical frequency modulation (EFM) technique. Corrosion Science 2006, 48, 965-979, https://doi.org/10.1016/j.corsci.2005.02.023.

46. Caignan, G.A.; Metcalf, S.K.; Holt, E.M. Thiophene substituted dihydropyridines. Journal of Chemical Crystallography 2000, 30, 415-422, https://doi.org/10.1023/a:1009538107356.

47. Abdel-Rehim, S.S.; Khaled, K.F.; Abd-Elshafi, N.S. Electrochemical frequency modulation as a new technique for monitoring corrosion inhibition of iron in acid media by new thiourea derivative. Electrochimica Acta 2006, 51, 3269-3277, https://doi.org/10.1016/j.electacta.2005.09.018. 
48. Ouakki, M.; Rbaa, M.; Galai, M.; Lakhrissi, B.; Rifi, E.H.; Cherkaoui, M. Experimental and Quantum Chemical Investigation of Imidazole Derivatives as Corrosion Inhibitors on Mild Steel in $1.0 \mathrm{M}$ Hydrochloric Acid. Journal of Bio- and Tribo-Corrosion 2018, 4, 35-46, https://doi.org/10.1007/s40735018-0151-2.

49. Aslam, R.; Mobin, M.; Aslam, J.; Lgaz, H.; Chung, I.-M. Inhibitory effect of sodium carboxymethylcellulose and synergistic biodegradable gemini surfactants as effective inhibitors for MS corrosion in $1 \mathrm{M} \mathrm{HCl}$. Journal of Materials Research and Technology 2019, 8, 4521-4533, http://dx.doi.org/10.1016/j.jmrt.2019.07.065.

50. Dehghani, A.; Bahlakeh, G.; Ramezanzadeh, B.; Ramezanzadeh, M. Potential of Borage flower aqueous extract as an environmentally sustainable corrosion inhibitor for acid corrosion of mild steel: Electrochemical and theoretical studies. Journal of Molecular Liquids 2019, 277, 895-911, https://doi.org/10.1016/j.molliq.2019.01.008.

51. Yurt, A.; Bereket, G.; Kivrak, A.; Balaban, A.; Erk, B. Effect of Schiff Bases Containing Pyridyl Group as Corrosion Inhibitors for Low Carbon Steel in 0.1 M HCl. Journal of Applied Electrochemistry 2005, 35 , 1025-1032, https://doi.org/10.1007/s10800-005-7336-3.

52. El Hamdani, N.; Fdil, R.; Tourabi, M.; Jama, C.; Bentiss, F. Alkaloids extract of Retama monosperma (L.) Boiss. seeds used as novel eco-friendly inhibitor for carbon steel corrosion in $1 \mathrm{M} \mathrm{HCl}$ solution: Electrochemical and surface studies. Applied Surface Science 2015, 357, 1294-1305, https://doi.org/10.1016/j.apsusc.2015.09.159.

53. Gao, X.; Liu, S.; Lu, H.; Gao, F.; Ma, H. Corrosion Inhibition of Iron in Acidic Solutions by Monoalkyl Phosphate Esters with Different Chain Lengths. Industrial \& Engineering Chemistry Research 2015, 54, 1941-1952, https://doi.org/10.1021/ie503508h.

54. Droulas, J. L.; Jugnet, Y., Duc, T. M. “In Situ” XPS Investigation of Polymers Metallized by Evaporation. Metallized Plastics 3. Mittal K.L. Springer, New York, US, 1992; pp. 123-140, https://doi.org/10.1007/9781-4615-3416-7_11.

55. Goldberg, M.J.; Clabes, J.G.; Kovac, C.A. Metal-polymer chemistry. II. Chromium-polyimide interface reactions and related organometallic chemistry. Journal of Vacuum Science \& Technology A 1988, 6, 991996, https://doi.org/10.1116/1.575006.

56. Gu, T.; Chen, Z.; Jiang, X.; Zhou, L.; Liao, Y.; Duan, M.; Wang, H.; Pu, Q. Synthesis and inhibition of Nalkyl-2-(4-hydroxybut-2-ynyl) pyridinium bromide for mild steel in acid solution: Box-Behnken design optimization and mechanism probe. Corrosion Science 2015, 90, 118-132, https://doi.org/10.1016/j.corsci.2014.10.004.

57. Chevalier, M.; Robert, F.; Amusant, N.; Traisnel, M.; Roos, C.; Lebrini, M. Enhanced corrosion resistance of mild steel in $1 \mathrm{M}$ hydrochloric acid solution by alkaloids extract from Aniba rosaeodora plant: Electrochemical, phytochemical and XPS studies. Electrochimica Acta 2014, 131, 96-105, https://doi.org/10.1016/j.electacta.2013.12.023.

58. Mourya, P.; Singh, P.; Tewari, A.K.; Rastogi, R.B.; Singh, M.M. Relationship between structure and inhibition behaviour of quinolinium salts for mild steel corrosion: Experimental and theoretical approach. Corrosion Science 2015, 95, 71-87, https://doi.org/10.1016/j.corsci.2015.02.034.

59. Brusic, V.; Frisch, M.A.; Eldridge, B.N.; Novak, F.P.; Kauman, F.B.; Rush, B.M.; Frankel, G.S. Copper Corrosion With and Without Inhibitors. J. Electrochem. Soc. 1991, 138, 2253-2259.

60. Le Mehaute, A.; Grepy, G. Introduction to transfer and motion in fractal media: The geometry of kinetics. Solid State Ionics 1989, 10, 1723-1731. 